\title{
AN UNMANNED AIRCRAFT MODEL FOR CONTROL SYSTEM RECONFIGURATION ANALYSIS AND SYNTHESIS
}

\author{
Marcin Żugaj*, Przemyseaw BibiK*, Marcin Figat ${ }^{* *}$ \\ * Zakład Automatyki i Osprzętu Lotniczego, Wydział Mechaniczny Energetyki i Lotnictwa, Politechnika \\ Warszawska (Division of Automation and Aeronautical Systems, Faculty of Power and Aeronautical Engineering, \\ Warsaw University of Technology), ul. Nowowiejska 24, 00-665 Warsaw \\ ** Zakład Samolotów i Śmigłowców, Wydział Mechaniczny Energetyki i Lotnictwa, Politechnika Warszawska \\ (Division of Aeroplanes and Helicopters, Faculty of Power and Aeronautical Engineering, Warsaw University \\ of Technology), ul. Nowowiejska 24, 00-665 Warsaw \\ zugaj@meil.pw.edu.pl,pbibik@meil.pw.edu.pl,mfigat@meil.pw.edu.pl
}

\begin{abstract}
Reliability of unmanned aircraft is a decisive factor for conducting air tasks in a controlled airspace. One of the means of improving unmanned aircraft reliability is reconfiguration of the control system, which will allow to maintain control over the aircraft despite an occurring failure. The control system is reconfigured by using still operational control surfaces to compensate for failure consequences and to control the damaged aircraft. Development of effective reconfiguration algorithms involves utilization of a non-linear model of unmanned aircraft dynamics, in which each control surface deflection can be controlled independently.

The paper describes a non-linear model of a small unmanned aircraft with decoupled control surfaces. The paper discusses aircraft flight dynamics equations and estimated equations for controllability derivatives for each control surface, the results of comparison tests of the model and actual aircraft as well as the structure of the simulation model. The developed unmanned aircraft model may be used in development and in optimization of control algorithms for aircraft with damaged control systems as well as to test the impact of failures on dynamic properties of the aircraft.
\end{abstract}

Keywords: flight dynamics, control, reconfiguration

\section{INTRODUCTION}

In recent years, rapid development of unmanned aerial vehicles both in military and in civilian applications can be noticed. On the civil market a number solutions for UAV systems have appeared, which are intended for commercial and personal use. One of the key issues related to development 
of unmanned UAV systems is their safety, which currently is insufficient to allow for air tasks to be performed in a controlled airspace [1]. Many research facilities around the world work on improving UAV systems safety to a level that would permit their integration with air traffic control systems [2],[3].

Safety of an unmanned system depends on the reliability of its components. There are methods which allow to reduce the effects of failures of individual system components. One of the main components of an UAV system, the reliability of which is the key factor for the aircraft usability in a controlled airspace, is the aircraft itself. Reliability of an unmanned aircraft depends on many factors, both external and internal, which include reliability of the control system [4]. Hardware redundancy is the key method used to ensure control systems' reliability in manned aircraft [5]. Some disadvantages of this method, which limit its applicability in unmanned aircraft, include high cost of such solutions and increased complexity of the control system, its weight and volume [6]. Therefore, it seems natural to utilize control system reconfiguration methods [7],[8]. Reconfiguration of the control system can be accomplished using numerical algorithms which are designed to use still operational control surfaces to compensate for effects of a failure [9]. The role of the reconfiguration is not to restore full functionality of the control system, but rather to ensure some degree of control which would allow the aircraft to be safely brought back to its launch zone, to be landed in an accidental area or at least to be crashed in a controlled manner outside built-up areas. Effectiveness of the control system reconfiguration depends mainly on the aircraft dynamic properties and on the airframe configuration, including the number and the type of control surfaces available. Therefore, in order to ensure the highest effectiveness of the reconfiguration, normally coupled control surfaces (e.g. as ailerons, elevators or flaps) are decoupled [6], [9]. Development of effective control system reconfiguration algorithms requires a number of studies to be conducted in order to assess the impact of a failure on the aircraft's dynamic properties and limits of control. To conduct such studies, it will be necessary to develop a mathematical and a simulated model of an aircraft with decoupled control surfaces, in which each control surface is modeled as an independent element generating aerodynamic forces and moments. Also, such model will be needed in order to perform analysis and synthesis of reconfiguration algorithms, to conduct hardware-in-theloop tests of the final control system and to conduct studies of control system reconfiguration's impact on pilot's/operator's perception (human-machine interaction) [11].

This paper presents a nonlinear mathematical model and a simulation model of an unmanned aircraft with decoupled control surfaces, with special focus on incorporation of estimated aerodynamic loading generated by individual control surfaces. An indirect model of controllability derivatives for decoupled control surfaces, with values determined with reference to derivatives of coupled surfaces has been proposed, which allows for the aircraft model to be adjusted and adapted to match any type of aircraft. Additionally the paper presents results of the model validation performed using results of in-flight tests and results of real-time simulation performed in a test simulator. 


\section{A MODEL OF AN UNMANNED AIRCRAFT WITH DECOUPLED CONTROL SURFACES}

\subsection{Assumptions}

A nonlinear model of an unmanned aircraft dynamics was developed for analysis and synthesis of control algorithms for an aircraft with damaged control system. A small unmanned aircraft with a wingspan of $2.6 \mathrm{~m}$, a total length of $1.25 \mathrm{~m}$ and takeoff weight of up to $3 \mathrm{~kg}$ was selected for modeling. The aircraft was equipped with a power unit consisting of an electric motor with a fixed-pitch propeller in tractor configuration, installed in the nose part of the fuselage. The maximum thrust of the power unit was $10 \mathrm{~N}$. The aircraft had classic configuration of control surfaces consisting of: one pair of ailerons, one pair of flaps on the wing trailing edge, one pair of elevators and a rudder (fig. 1). The permissible deflection angles of individual control surfaces were: +15 i -20 degrees for ailerons, \pm 15 degrees for elevators, \pm 30 degrees for the rudder and +40 degrees for flaps. Downward deflection in case of ailerons, flaps and elevators and leftward deflection in case of the ruder were assumed as positive deflection angles. A standardized thrust control signal for the power unit varies in the $(0,1)$ range, where 0 corresponds to zero rpm and 1 to the maximum rpm of the engine.

The aircraft was modeled as a rigid body with six degrees of freedom, with mass-related parameters (weight, center of gravity location and moments of inertia) not changing in flight. Also a classic model of aerodynamic forces and moments was assumed [12], [13]. Due to the anticipated application of the model, the key assumption was that the control system actuators are decoupled, that is that each control surface can be deflected independently. The model omitted dynamics of servomechanisms moving control surfaces, assuming that their inertia is small compared to the inertia of the aircraft itself. Additionally it was assumed that the aircraft will travel with a cruising speed of about $16 \mathrm{~m} / \mathrm{s}$ at the altitude of up to $30 \mathrm{~m}$.

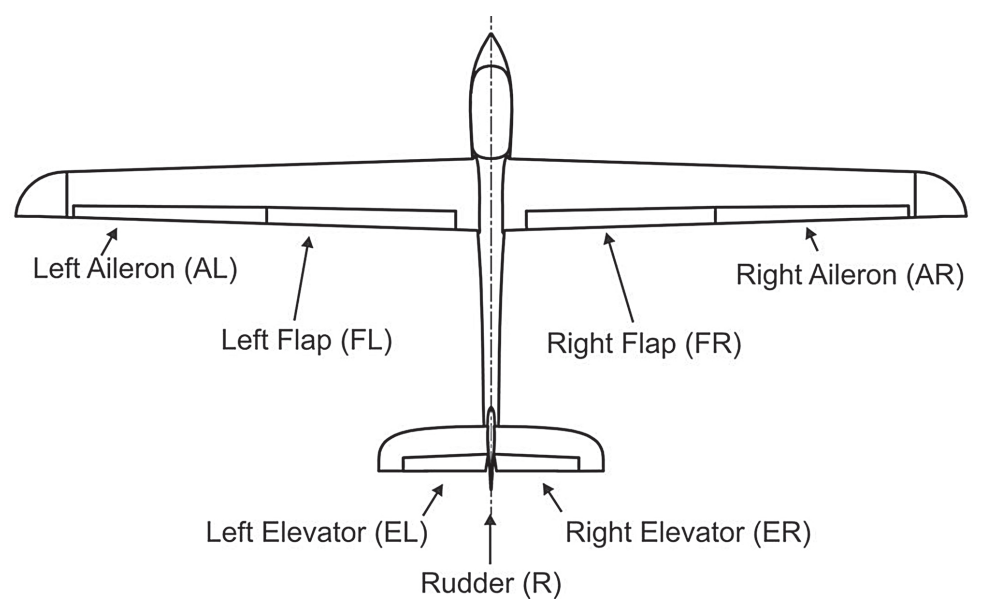

Fig. 1. Configuration of the control system [own study, 2014] 
For the spatial description of the aircraft motion the following Cartesian right-hand coordinate systems have been assumed (fig. 2):

- inertial, stationary coordinate system $\mathrm{O}_{n} \mathrm{x}_{n} y_{n} z_{n}$, with the origin $\mathrm{O}_{\mathrm{n}}$ located at an arbitrary point on the earth surface, the direction of the axis $\mathrm{O}_{\mathrm{n}} \mathrm{z}_{\mathrm{n}}$ axis is coincident with the direction and sense of the earth acceleration vector, the $\mathrm{O}_{n} x_{n} y_{n}$ plane is tangent to the earth surface, the $O_{n} x_{n}$ axis is directed towards the north geographic pole with the $\mathrm{O}_{n} \mathrm{y}_{\mathrm{n}}$ axis completing the right-hand system directed east,

- gravitational coordinate system $\mathrm{O}_{\mathrm{g}} \mathrm{x}_{\mathrm{g}} \mathrm{y}_{\mathrm{g}} \mathrm{z}_{\mathrm{g}}$ is related to a moving object, with the system's origin $\mathrm{O}_{\mathrm{g}}$ located at the aircraft's center of gravity, and the coordinate system is translated in parallel, relative to the $\mathrm{O}_{\mathrm{n}} \mathrm{x}_{\mathrm{n}} \mathrm{y}_{\mathrm{n}} \mathrm{z}_{\mathrm{n}}$ inertial system, and senses of both systems' axes are matching,

- the $\mathrm{O}_{\mathrm{b}} \mathrm{x}_{\mathrm{b}} \mathrm{y}_{\mathrm{b}} \mathrm{z}_{\mathrm{b}}$ coordinate system is associated with the aircraft; the origin of the system $\mathrm{O}_{\mathrm{b}}$ matches the origin of the gravitational system $\mathrm{O}_{\mathrm{g}}$, with the $\mathrm{O}_{\mathrm{b}} \mathrm{x}_{\mathrm{b}}$ axis lying in the aircraft's plane of symmetry $\mathrm{O}_{\mathrm{b}} \mathrm{x}_{\mathrm{b}} \mathrm{z}_{\mathrm{b}}$ and is directed towards the front of the aircraft's fuselage; the $\mathrm{O}_{\mathrm{b}} \mathrm{z}_{\mathrm{b}}$ axis is directed "down", with positive sense towards the aircraft's landing gear, and the $\mathrm{O}_{b} \mathrm{y}_{\mathrm{b}}$ axis completes the right-handed system and is directed towards the right wing.

- the $\mathrm{O}_{\mathrm{A}} \mathrm{x}_{\mathrm{A}} \mathrm{y}_{\mathrm{A}} \mathrm{z}_{\mathrm{A}}$ aerodynamic coordinate system is related to the orientation of the inflow speed vector; the $\mathrm{O}_{\mathrm{A}} \mathrm{x}_{\mathrm{A}} \mathrm{z}_{\mathrm{A}}$ plane lies in the plane of the aircraft's symmetry; the origin of the coordinate system is located in the center of the aircraft gravity; the $\mathrm{O}_{\mathrm{A}} \mathrm{x}_{\mathrm{A}}$ axis direction and sense match the aircraft airspeed vector; the $\mathrm{O}_{\mathrm{A}} \mathrm{z}_{\mathrm{A}}$ axis is directed downwards and the $\mathrm{O}_{\mathrm{A}} \mathrm{y}_{\mathrm{A}}$ axis towards the right wing tip. The $\mathrm{O}_{A} \mathrm{x}_{A} \mathrm{y}_{A} \mathrm{z}_{A}$ system is rotated relative to the $\mathrm{O}_{b} \mathrm{x}_{b} \mathrm{y}_{\mathrm{b}} \mathrm{z}_{\mathrm{b}}$ system in the $\mathrm{O}_{\mathrm{b}} \mathrm{x}_{\mathrm{b}} \mathrm{z}_{\mathrm{b}}$ plane by the angle of attack $\alpha$.

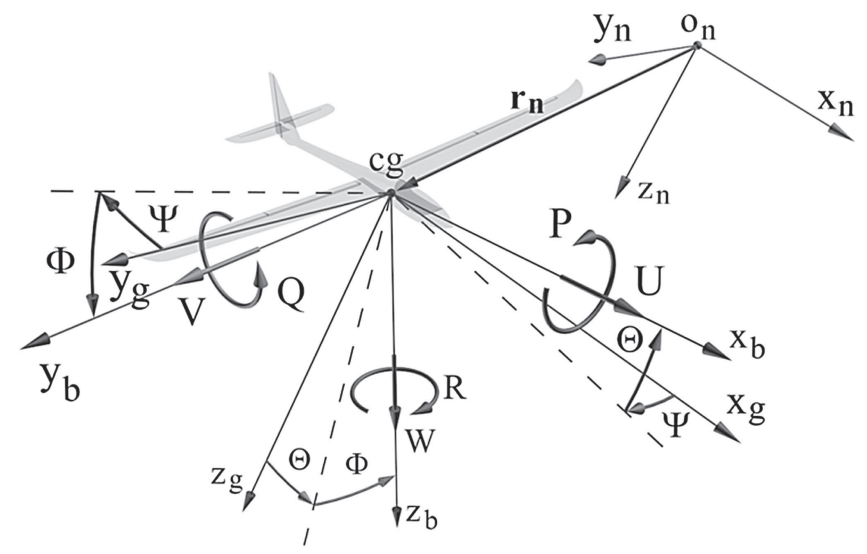

Fig. 2. Coordinate systems [own study, 2016]

\subsection{Nonlinear equations of the aircraft motion}

The aircraft motion equations were derived in the coordinate system associated with the aircraft $0_{b} x_{b} y_{b} z_{b}$. Aircraft state vector $\mathbf{x}$ contains linear velocity components $\quad \mathbf{v}=\left[\begin{array}{lll}U & V & W\end{array}\right]$ ( $U$ - longitudinal speed, $V$ - lateral speed, $W$ - vertical speed) and angular velocity components $\boldsymbol{\omega}=\left[\begin{array}{lll}P & Q & R\end{array}\right](P$-roll angularvelocity, $Q$-pitch angularvelocity, $R$-yaw angular velocity) (fig. 2$)$. 
The aircraft position and orientation are described by the $\mathbf{y}=\left[\begin{array}{lllllll}x_{n} & y_{n} & z_{n} & \Phi & \Theta & \Psi\end{array}\right]^{\mathrm{T}}$ vector, where $x_{n}, y_{n}, z_{n}$ are vector components of the aircraft's COG location $\mathbf{r}_{\mathbf{n}}$ in the navigational coordinate system $O_{n} x_{n} y_{n} z_{n}, \Phi$ is the roll angle, $\Theta$ is the pitch angle and $\Psi$ is the aircraft yaw angle (fig 2).

The relationships between the state vector $\mathbf{x}=\left[\begin{array}{llllll}U & V & W & P & Q & R\end{array}\right]^{\mathrm{T}}$ and the spatial orientation and position vector $\mathbf{y}$ are described by the equation [12],[13]:

$$
\dot{\mathbf{y}}=\mathbf{T} \mathbf{x},
$$

where the matrix $\mathbf{T}$ has the form of:

$$
\mathbf{T}=\left[\begin{array}{cc}
\mathbf{T}_{\mathbf{V}} & \mathbf{0} \\
\mathbf{0} & \mathbf{T}_{\mathbf{\Omega}}
\end{array}\right],
$$

whereas [12], [13]:

$$
\begin{aligned}
& \mathbf{T}_{\mathbf{V}}=\left[\begin{array}{ccc}
\cos \Theta \cdot \cos \Psi & \sin \Theta \cdot \sin \Phi \cdot \cos \Psi-\cos \Phi \cdot \sin \Psi & \cos \Phi \cdot \sin \Theta \cdot \cos \Psi+\sin \Phi \cdot \sin \Psi \\
\cos \Theta \cdot \sin \Psi & \sin \Theta \cdot \sin \Phi \cdot \sin \Psi+\cos \Phi \cdot \cos \Psi & \cos \Phi \cdot \sin \Theta \cdot \sin \Psi-\sin \Phi \cdot \cos \Psi \\
-\sin \Theta & \sin \Phi \cdot \cos \Theta & \cos \Phi \cdot \cos \Theta
\end{array}\right], \\
& \mathbf{T}_{\mathbf{\Omega}}=\left[\begin{array}{ccc}
1 & \sin \Phi \cdot \tan \Theta & \cos \Phi \cdot \tan \Theta \\
0 & \cos \Phi & -\sin \Phi \\
0 & \sin \Phi \cdot \sec \Theta & \cos \Phi \cdot \sec \Theta
\end{array}\right] .
\end{aligned}
$$

The general form of aircraft motion equations is described by [12], [13]:

$$
\begin{aligned}
& \mathbf{A} \dot{\mathbf{x}}+\mathbf{B x}=\mathbf{f}_{\mathbf{A}}+\mathbf{f}_{\mathbf{G}}+\mathbf{f}_{\mathbf{T}}, \\
& \mathbf{B}=\mathbf{\Omega} \mathbf{A},
\end{aligned}
$$

where matrices $\mathbf{A}$ and $\Omega$ have the following forms [12], [13]:

$$
\mathbf{A}=\left[\begin{array}{cccccc}
m & 0 & 0 & 0 & 0 & 0 \\
0 & m & 0 & 0 & 0 & 0 \\
0 & 0 & m & 0 & 0 & 0 \\
0 & 0 & 0 & I_{x} & 0 & -I_{x z} \\
0 & 0 & 0 & 0 & I_{y} & 0 \\
0 & 0 & 0 & -I_{x z} & 0 & I_{z}
\end{array}\right], \boldsymbol{\Omega}=\left[\begin{array}{cccccc}
0 & -R & Q & 0 & 0 & 0 \\
R & 0 & -P & 0 & 0 & 0 \\
-Q & P & 0 & 0 & 0 & 0 \\
0 & -W & V & 0 & -R & Q \\
W & 0 & -U & R & 0 & -P \\
-V & U & 0 & -Q & P & 0
\end{array}\right],
$$

whereas $m$ is the aircraft weight, $I_{x}, I_{y}, I_{z}$ are aircraft moments of inertia and $I_{x z}$ is the deviation moment of inertia.

The gravity force vector acting on the aircraft is described by the equation [12], [13]:

$$
\mathbf{f}_{\mathbf{g}}=m g\left[\begin{array}{c}
-\sin \Theta \\
\cos \Theta \cdot \sin \Phi \\
\cos \Theta \cdot \cos \Phi
\end{array}\right],
$$

where: $g$ is the value of the gravitational acceleration. Therefore, the vector describing loading from the gravitational force has the form of:

$$
\mathbf{f}_{\mathbf{G}}=\left[\begin{array}{llll}
\mathbf{f}_{\mathbf{g}}{ }^{\mathbf{T}} & 0 & 0 & 0
\end{array}\right]^{T} .
$$


Thrust generated by the power unit of the aircraft has been estimated in the course of tests conducted in a wind tunnel. During these tests the thrust of the power unit, the velocity of the air stream flowing around the propeller and the power unit control signal were recorded. The power unit of the aircraft is controlled by a pulse width modulated (PWM) control signal, therefore the recorded control signal was the duty cycle of the $u_{T}$ pulse. Thrust has been derived as a function of a standardized power unit control signal $\delta_{T}$ and the longitudinal speed $U$ :

$$
\begin{aligned}
& F_{T}\left(\delta_{T}, U\right)=a(U) F_{T 0}^{2}\left(u_{T}\right)+b(U) F_{T 0}\left(u_{T}\right)+c(U), \\
& u_{T}=0.56 \delta_{T}+1,16,
\end{aligned}
$$

whereas the equation $(10 \mathrm{~b})$ presents standardization of the control signal, that is the relation of the PWM signal pulse $u_{T}$ duty cycle to the standardized control signal $\delta_{T}$ used in the aircraft model while other components of the equation (10a) are described by the following dependencies:

$$
\begin{aligned}
& F_{T 0}\left(u_{T}\right)=34,752 u_{T}^{4}-194,3 u_{T}^{3}+411,07 u_{T}^{2}-378,4 u_{T}+125,51, \\
& a(U)=-1,0396 \cdot 10^{-5} U^{3}+0,00028263 U^{2}+0,00023321 U-0,032234, \\
& b(U)=0,00089355 U^{2}-0,063562 U+1,7984, \\
& c(U)=-0,11747 U+1,8852 .
\end{aligned}
$$

Comparison of characteristics measured and computed using the model, which illustrate the dependency of the thrust on the control signal for longitudinal speeds in the range from 4 to $20 \mathrm{~m} / \mathrm{s}$ is shown in figure 3.

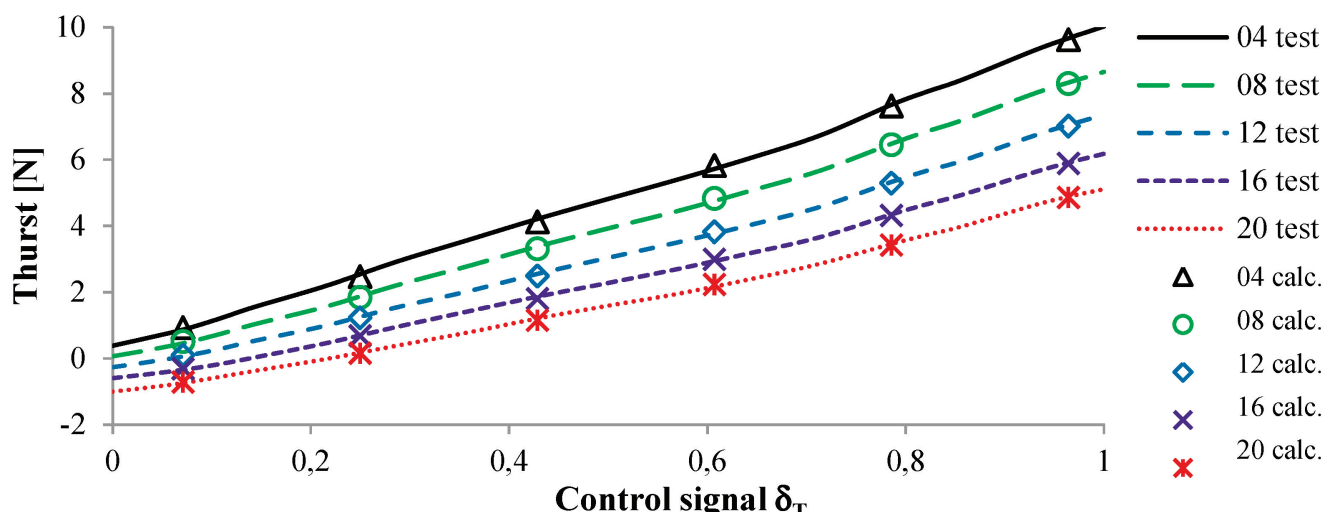

Fig. 3. Thrust characteristics for various inflow speeds ("test" - wind tunnel test results, "calc." - results calculated according to the model) [own study: 2016] 
The power unit's thrust vector shall have the form:

$$
\mathbf{f}_{\mathbf{t}}=\left[\begin{array}{lll}
F_{T} & 0 & 0
\end{array}\right]^{T},
$$

whereas the vector of the moment resulting from the thrust force:

$$
m_{t}=r_{t} \times f_{t},
$$

where: $\mathbf{r}_{\mathbf{t}}$ is a vector describing location of the thrust force vector $\mathbf{f}_{\mathbf{t}}$ in the aircraft's coordinate system $O_{b} x_{b} y_{b} z_{b}$.

Therefore the loading vector from the power unit is:

$$
\mathbf{f}_{\mathrm{T}}=\left[\begin{array}{ll}
\mathbf{f}_{\mathbf{t}} & \mathbf{m}_{\mathbf{t}}
\end{array}\right]^{T} \text {. }
$$

The aerodynamic loading vector shall have the following form:

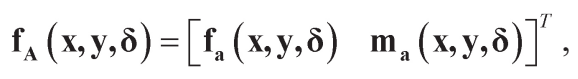

whereas the control vector has the following components [14]:

$$
\boldsymbol{\delta}=\left[\begin{array}{lllllll}
\delta_{A R} & \delta_{A L} & \delta_{E R} & \delta_{E L} & \delta_{F R} & \delta_{F L} & \delta_{R}
\end{array}\right]^{T},
$$

where: $\delta_{A R}$ - right aileron deflection angle, $\delta_{A L}$ - left aileron deflection angle, $\delta_{E R}-$ right elevator deflection angle, $\delta_{E L}-$ left elevator deflection angle, $\delta_{F R}-$ right flap deflection angle, $\delta_{F L}-$ left aileron deflection angle, $\delta_{R}$ - rudder deflection angle [15].

The aerodynamic model of the aircraft was developed based on aerodynamic properties captured using analytical and numerical methods [16],[17]. For numerical analyses [18] (figure 4) MGAERO software was used. It utilizes Computational Fluid Dynamics (CFD) methods and XFLR [19] and Xfoil [20] software based on the panel method. The final form of the model is a compilation of all these characteristics and its result constitutes a comprehensive aerodynamic model of an aircraft with uncoupled control surfaces. According to the assumption made, a classic aerodynamic loading model has been developed. Aerodynamic forces and moments are calculated as the sum of the forces and moments determined for a neutral position of the control surfaces as functions of angle of attack $\alpha$ and glide angle $\beta$ (static forces and moments), aerodynamic moments and forces resulting from changes of momentary angular velocities and linear speed derivatives as well as aerodynamic forces and moments caused by control surface deflection [12],[13],[21]. Thus the aerodynamic force and moment vectors are:

$$
\begin{aligned}
& \mathbf{f}_{\mathrm{a}}=\mathbf{F}_{\mathrm{AS}}+\mathbf{F}_{\mathrm{A} \boldsymbol{}}+\mathbf{F}_{\mathrm{AW}}+\mathbf{F}_{\mathrm{A} \delta}, \\
& \mathbf{m}_{\mathbf{a}}=\mathbf{M}_{\mathrm{AS}}+\mathbf{M}_{\mathrm{A} \boldsymbol{\Omega}}+\mathbf{M}_{\mathrm{AW}}+\mathbf{M}_{\mathrm{AV}}+\mathbf{M}_{\mathrm{A} \delta},
\end{aligned}
$$

where the AS index refers to static aerodynamic loading, $A \Omega$ refers to angular speed derivatives, $\mathrm{AV}$ refers to lateral speed derivatives, $\mathrm{AW}$ refers to vertical acceleration derivatives, and $\mathrm{A} \delta$ refers to control variable derivatives. 
Vectors of the aerodynamic force and of the aerodynamic moment are given by:

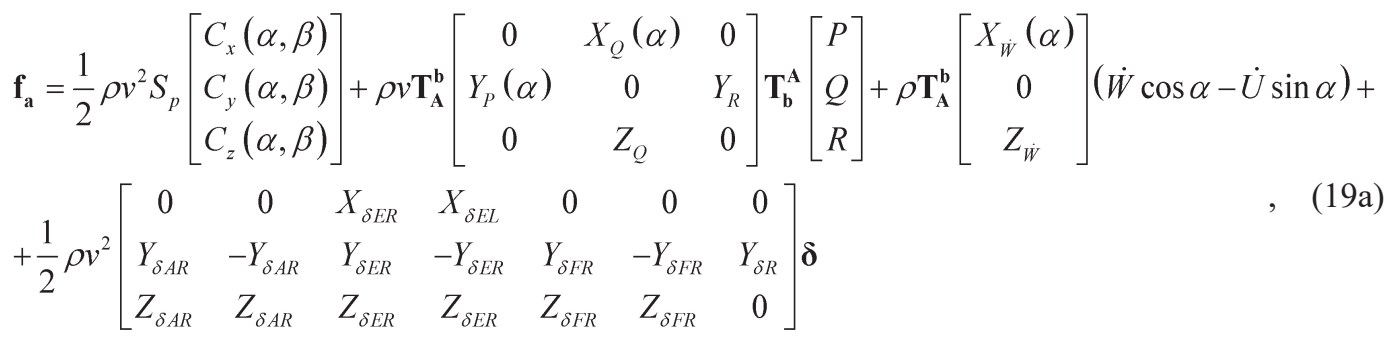
$\mathbf{m}_{\mathbf{a}}=\frac{1}{2} \rho v^{2} S_{p}\left[\begin{array}{c}C_{m x} b \\ C_{m y} \bar{c} \\ C_{m z} b\end{array}\right]+\rho v \mathbf{T}_{\mathbf{A}}^{\mathbf{b}}\left[\begin{array}{ccc}L_{P} & 0 & L_{R}(\alpha) \\ 0 & M_{Q} & 0 \\ N_{P}(\alpha) & 0 & N_{R}(\alpha)\end{array}\right] \mathbf{T}_{\mathbf{b}}^{\mathbf{A}}\left[\begin{array}{c}P \\ Q \\ R\end{array}\right]+\rho\left[\begin{array}{c}0 \\ M_{\dot{W}} \\ 0\end{array}\right](\dot{W} \cos \alpha-\dot{U} \sin \alpha)_{+}$

$+\rho v\left[\begin{array}{c}L_{V}(\alpha) \\ 0 \\ 0\end{array}\right] V+\frac{1}{2} \rho v^{2}\left[\begin{array}{ccccccc}L_{\delta A R} & -L_{\delta A R} & L_{\delta E R} & -L_{\delta E R} & L_{\delta F R} & -L_{\delta F R} & L_{\delta R}{ }^{b} \\ M_{\delta A R} & M_{\delta A R} & M_{\delta E R} & M_{\delta E R} & M_{\delta F R} & M_{\delta F R} & 0 \\ N_{\delta A R} & -N_{\delta A R} & N_{\delta E R} & -N_{\delta E R} & N_{\delta F R} & -N_{\delta F R} & N_{\delta R}^{b}\end{array}\right] \boldsymbol{\delta}$

where: $v$ - is the undisturbed flow speed, $\rho$ - air density, $S_{p}$ - reference surface area, $\bar{c}-$ mean aerodynamic chord, $b$ - wing span, $C_{x}, C_{y}, C_{z}$ - dimensionless coefficients of aerodynamic forces, $C_{m x}, C_{m y}, C_{m z}-$ dimensionless coefficients of aerodynamic moments, $X_{i}, Y_{i}, Z_{i}$ - derivatives of stability and aerodynamic force control, $L_{i} M_{i} N_{i}$ - derivatives of stability and aerodynamic moment control, $\mathbf{T}_{\mathbf{A}}^{\mathbf{b}}$ - matrix of transformation from the $\mathrm{O}_{\mathrm{A}} \mathrm{x}_{\mathrm{A}} \mathrm{y}_{\mathrm{A}} \mathrm{z}_{\mathrm{A}}$ system to the $\mathrm{O}_{\mathrm{b}} \mathrm{x}_{\mathrm{b}} \mathrm{y}_{\mathrm{b}} \mathrm{z}_{\mathrm{b}}$ system:

$$
\mathbf{T}_{\mathbf{A}}^{\mathbf{b}}=\left(\mathbf{T}_{\mathbf{b}}^{\mathbf{A}}\right)^{-1}=\left[\begin{array}{ccc}
\cos \alpha & 0 & -\sin \alpha \\
0 & 1 & 0 \\
\sin \alpha & 0 & \cos \alpha
\end{array}\right]
$$

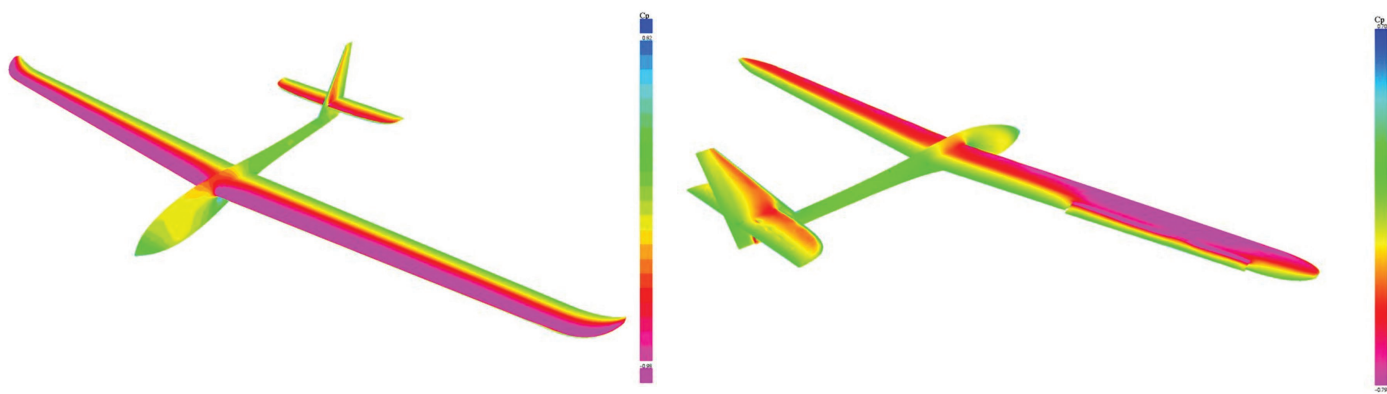

Fig. 4. Sample results of pressure distribution on a wing, generated using the MGAERO software (left - 5 degrees angle of attack, right 0 degrees angle of attack with right aileron deflected) [own study, 2016]

Controllability derivatives have been estimated indirectly. Their values have been determined with reference to maximum values of aerodynamic forces and moments from control for a classic, non-uncoupled control system. The reference value is a derivative of the rudder, which is leading for a given component of force or moment. For example, for the elevator the reference value for the 
derivative of the pitching moment is the maximum value of this derivative in a non-uncoupled system, and for the aileron the reference value for the roll moment is the value of this derivative in a non-uncoupled system. This solution facilitates adjustments of derivatives based on results of in-flight tests, in a situation when uncoupling of control surfaces during a test flight is not possible. Also, it allows for easy adaptation of the aerodynamic model to match any type of aircraft.

Derivatives of aerodynamic force and moment of controllability in a system associated with the aircraft $0_{b} x_{b} y_{b} z_{b}$ is given by the following equations:

$$
\begin{aligned}
& X_{\delta E R}=0.5 \cdot\left(X_{\delta E} \cos \alpha-Z_{\delta E} \sin \alpha\right), \\
& Y_{\delta A R}=\Delta Y_{A} Y_{\delta R} \frac{\delta_{R \max }}{\delta_{A \max }}, \\
& Y_{\delta E R}=\Delta Y_{E} Y_{\delta R} \frac{\delta_{R \max }}{\delta_{E \max }}, \\
& Y_{\delta F R}=\Delta Y_{F} Y_{\delta R} \frac{\delta_{R \max }}{\delta_{F \max }}, \\
& Z_{\delta A R}=\Delta Z_{A} Z_{\delta E} \frac{\delta_{E \max }}{\delta_{A \max }}, \\
& Z_{\delta E R}=\Delta Z_{E} Z_{\delta E}, \\
& Z_{\delta F R}=\Delta Z_{F} Z_{\delta E} \frac{\delta_{E \max }}{\delta_{F \max }}, \\
& L_{\delta A R}=\Delta L_{A} L_{\delta A}, \\
& L_{\delta E R}=\Delta L_{E} L_{\delta A} \frac{\delta_{A \max }}{\delta_{E \max }}, \\
& L_{\delta F R}=\Delta L_{F} L_{\delta A} \frac{\delta_{A \max }}{\delta_{F \max }},
\end{aligned}
$$

where $X_{\delta E}, Z_{\delta E}, Y_{\delta R}, L_{\delta A}, M_{\delta E}, N_{\delta R}$ are control derivatives for non-uncoupled (classic) control system, which can be determined classically using analytical methods.

Results of numerical computations of control derivatives for uncoupled control surfaces were used to determine scaling coefficient functions. First, values of derivatives for individual components of the aerodynamic force and moment were calculated, for full ranges of control surface deflections (with 5 degree step). Next, derivatives variability functions of control surface deflections were determined and their ratios to maximum values of control derivatives in non-uncoupled configuration were determined. Scaling coefficients of controllability derivatives for the modeled aircraft are: 


$$
\begin{aligned}
& \Delta Z_{A}=\left\{\begin{array}{lll}
1.643 \delta_{A i}+0.887 & \text { dla } & \delta_{A i}>0 \\
1.447 & \text { dla } & \delta_{A i}<0
\end{array},\right. \\
& \Delta M_{A}=\left\{\begin{array}{lll}
-0.445 \delta_{A i}{ }^{2}-0.011 \delta_{A i}+0.13 & \text { dla } & \delta_{A i}>0 \\
0.094 \delta_{A i}+0.128 & \text { dla } & \delta_{A i}<0
\end{array},\right. \\
& \Delta Y_{F}=\left\{\begin{array}{lll}
-0.02 \delta_{F i}^{2}+0.079 \delta_{F i}-0.047 & \text { dla } & \delta_{F i}>0 \\
0.275 \delta_{F i}-0.021 & \text { dla } & \delta_{F i}<0
\end{array}\right. \text {, } \\
& \Delta Z_{F}=-1.73 \delta_{F i}^{2}-0.56 \delta_{F i}+4.457, \\
& \Delta L_{F}=-0.319 \delta_{F i}^{2}-0.031 \delta_{F i}+0.652, \\
& \Delta M_{F}=\left\{\begin{array}{lll}
-0.258 \delta_{F i}{ }^{2}+0.261 \delta_{F i}-0.104 & \text { dla } & \delta_{F i}>0 \\
0.105 \delta_{F i}-0.02 & \text { dla } & \delta_{F i}<0
\end{array},\right. \\
& \Delta N_{F}=0.701 \delta_{F i}{ }^{3}-0.421 \delta_{F i}{ }^{2}-0.435 \delta_{F i}+0.193 \text {, } \\
& \Delta Y_{A}=-0.091 \text {, } \\
& \Delta L_{A}=0.489,
\end{aligned}
$$$$
\Delta Y_{E}=0.071 \text {, }
$$$$
\Delta Z_{E}=0.484,
$$$$
\Delta L_{E}=0.02,
$$$$
\Delta M_{E}=0.474,
$$$$
\Delta N_{E}=0.076,
$$$$
\Delta N_{A}=-0.363 \delta_{A i}-0.053,
$$

where index $i$ denotes $R$ or $L$ depending on whether the coefficient is related to the left or to the right control surface.

\subsection{Validation of an unmanned aircraft non-linear model}

In order to validate the developed model, the results obtained in the simulation were compared with the results obtained during in-flight testing. In-flight tests were conducted for stable, horizontal flights with speed of $16 \mathrm{~m} / \mathrm{s}$, at the altitude of $20 \mathrm{~m}$, in calm weather conditions. The in-flight testing involved recording of changes of aircraft state variables with the aircraft in a steady state, in response to given control signals. Tests were performed for non-uncoupled control system (ailerons and elevators working in pairs), by outputting to individual control channels typical signals which are used for aircraft's dynamic property tests or for dynamic property determination [21], [23]. For longitudinal motion, single rectangular pulse signals or multiple (“3-2-1-1") rectangular signals (fig. 5) were output to the coupled elevator control surface $\delta_{E}$. For lateral motion tests, dual rectangular pulse signals ("doublet") were output to the rudder $\delta_{R}$ and multiple rectangular pulse signals ("bank-to-bank") were output to ailerons $\delta_{A}$ (fig. 8). These signals were automatically generated by the on-board computer, after previous manual trimming of the aircraft for a stable horizontal flight. During execution of maneuvers, the computer was recording measurements with the frequency of $50 \mathrm{~Hz}$ for spatial orientation measurements and for linear acceleration and with the frequency of $10 \mathrm{~Hz}$ for aerometric data measurements based on which the barometric altitude and airspeed were calculated. 
During simulation tests, the same flight conditions were recreated, the same mass parameters of the aircraft were assumed and identical control signals were generated, as during the in-flight testing.

The discovered differences between the model and the actual aircraft behaviors resulted from underestimation of mass parameters, coefficients and aerodynamic derivatives and simplifying assumptions that were used in the model. Underestimation of aerodynamic coefficients could have resulted from inaccurate computations, inadequate representation of the aircraft geometry or imperfect manufacturing of the actual aircraft (inaccurate execution of its geometry, the quality of the obtained airframe structure surface, etc.). Based on the comparison of simulation results and in-flight tests, corrections of some coefficient and aerodynamic derivative values were introduced, which significantly improved the model quality.

Results of the corrected model simulation were compared with the results obtained for three repetitions of the same maneuver performed during the in-flight test. Figures 6 and 7 show the change of the pitch angle in response to forced pulse signals and "3-2-1-1" output to the elevator. Figures 9 and 10 show the change of the roll and yaw angles in response to a "doublet" signal output to the rudder. The comparison of the roll and yaw angle waveforms in the "bank-to-bank" test are shown in figures 11 and 12. Conducted comparison tests have proven that the developed model of unmanned aircraft flight dynamics is correct and corresponds to the physical object. Changes in time of state variables for the actual aircraft and for the model are similar. Visible differences resulted from both accuracy of the model itself and from the accuracy of conditions recreated in simulation testing, assumed for the in-flight tests. The accuracy of the simulation model depends on the quality of estimated aerodynamic and mass parameters and on the simplifying assumptions made during the model development. Validation of the model during in-flight testing permitted improvement of its quality by adjusting the values of estimated parameters, but it does not warrant full compatibility with the actual aircraft due to the assumed form of aerodynamic loading model and simplifying assumptions.

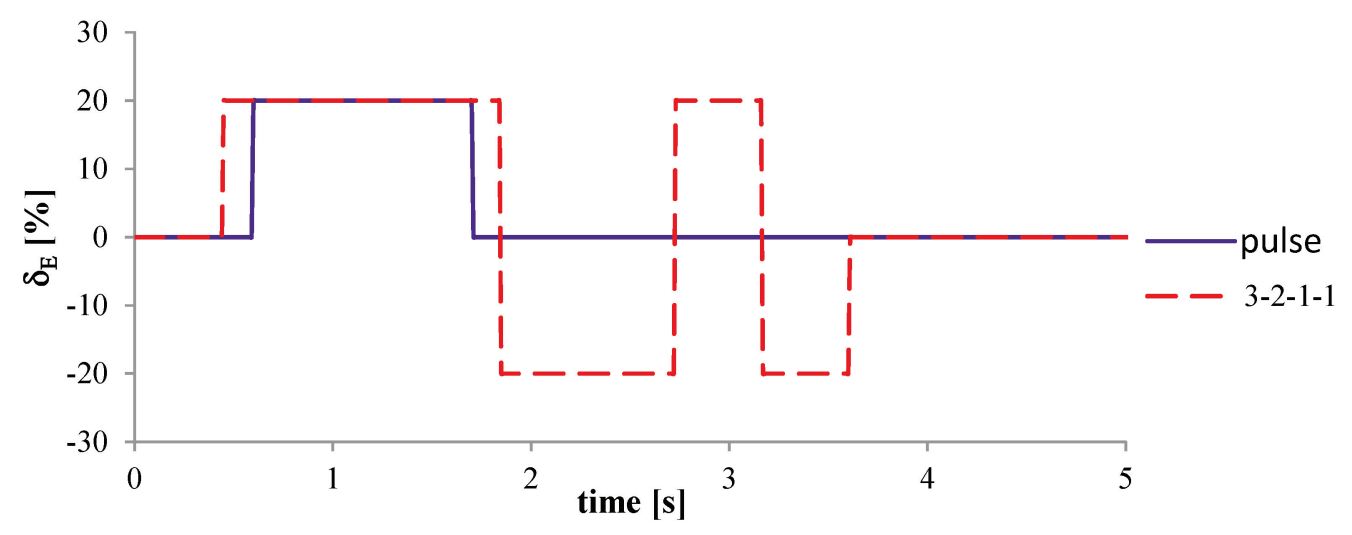

Fig. 5. Rectangular pulse and "3-2-1-1" pulse signals to elevators [own study, 2016] 


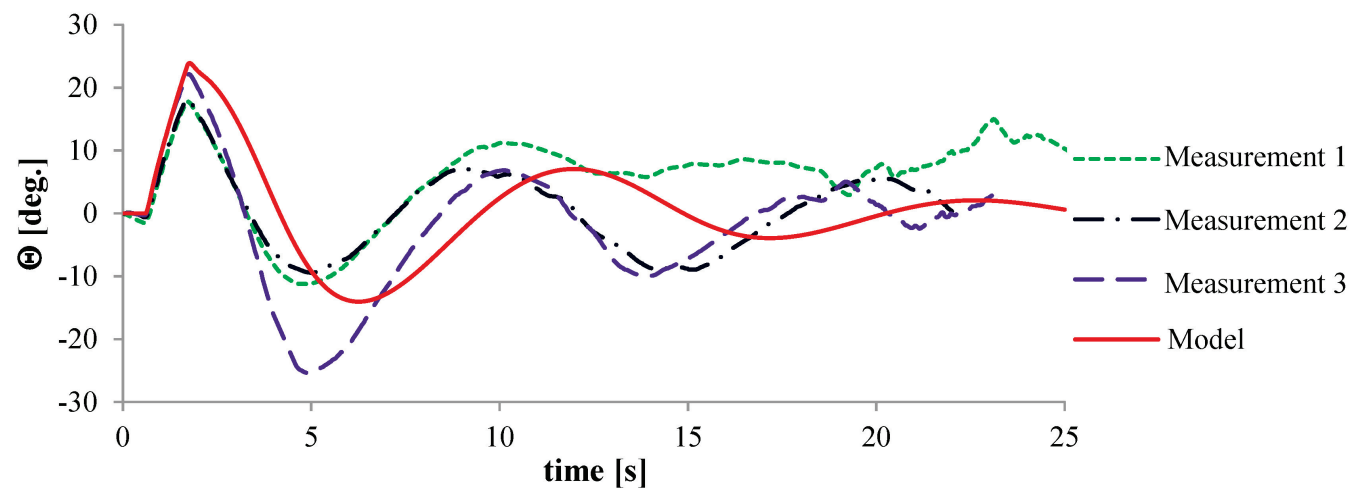

Fig. 6. Change of the pitch angle for pulsed deflection of elevators [own study, 2016]

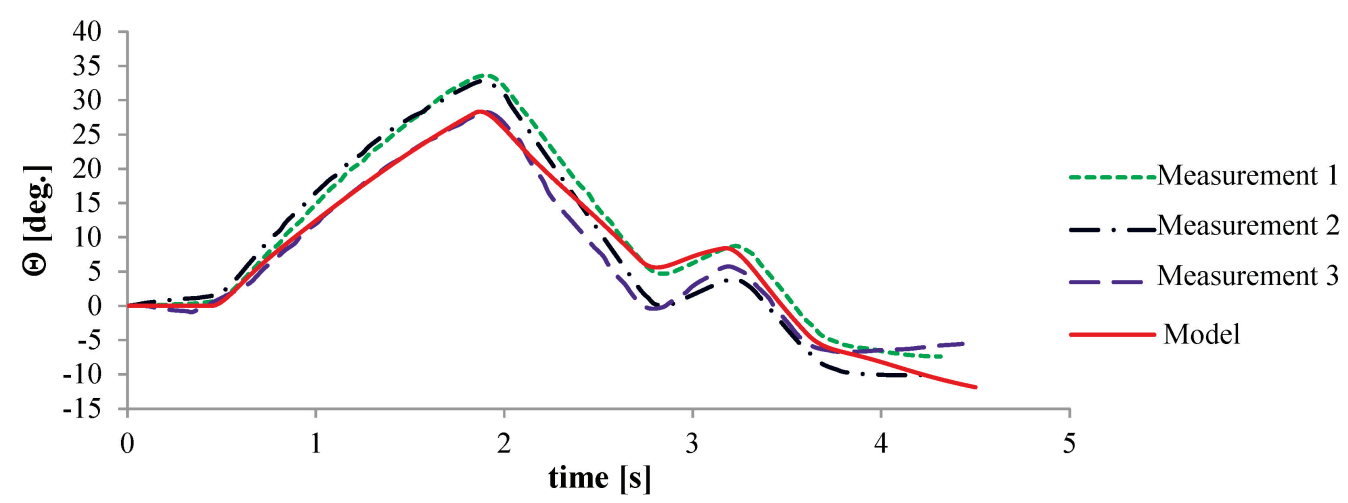

Fig. 7. Change of the pitch angle for the "3-2-1-1" signal output to elevators [own study, 2016]

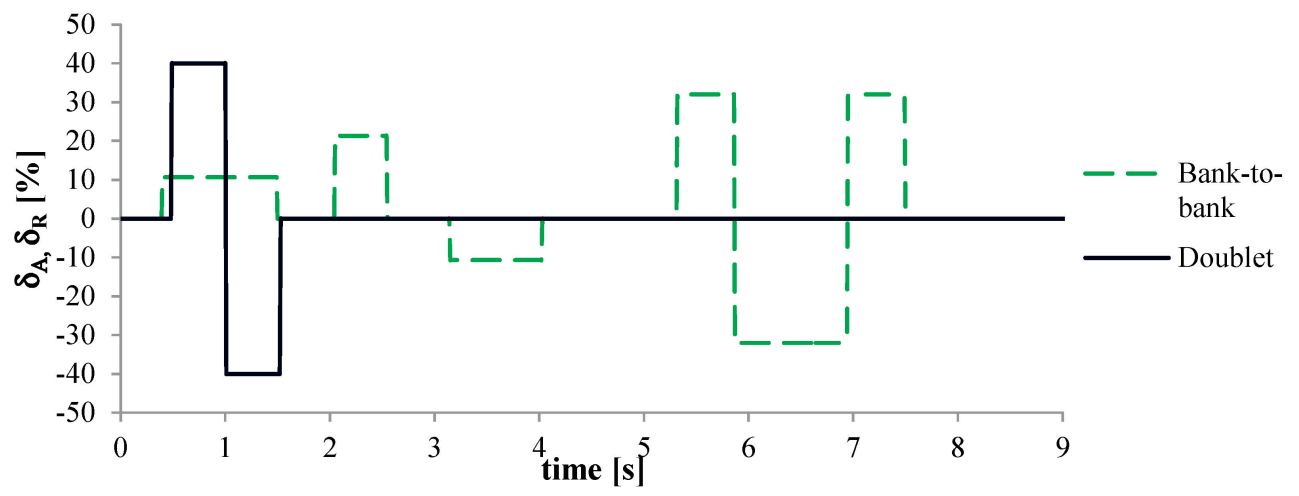

Fig. 8. A "doublet" signal and a "bank-to-bank" signal output to the rudder and to ailerons [own study, 2016] 


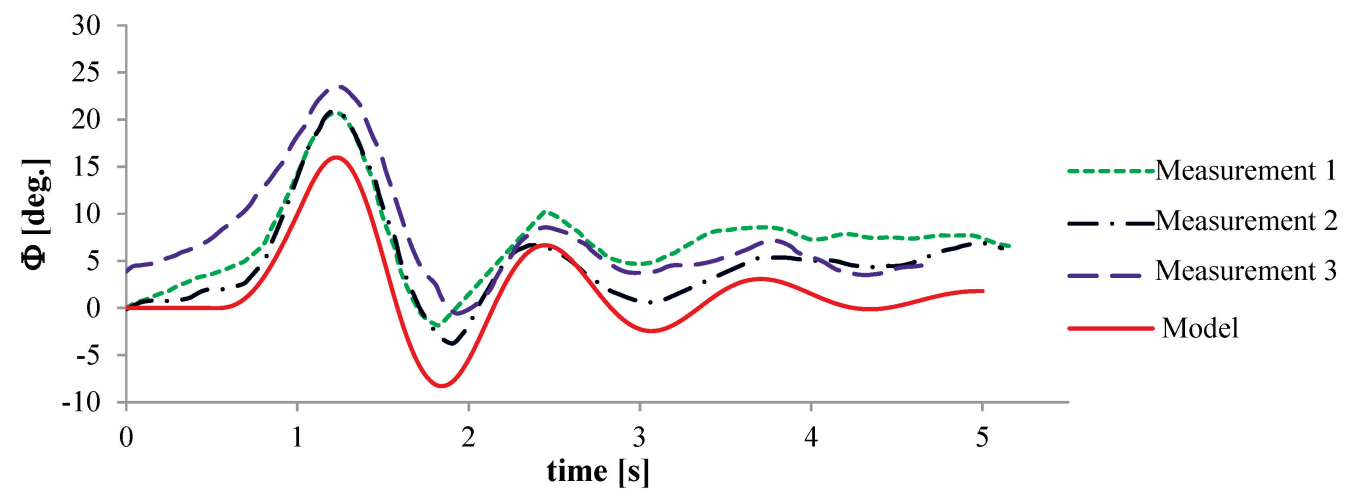

Fig. 9. Change of the roll angle for the "doublet" signal output to the rudder [own study, 2016]

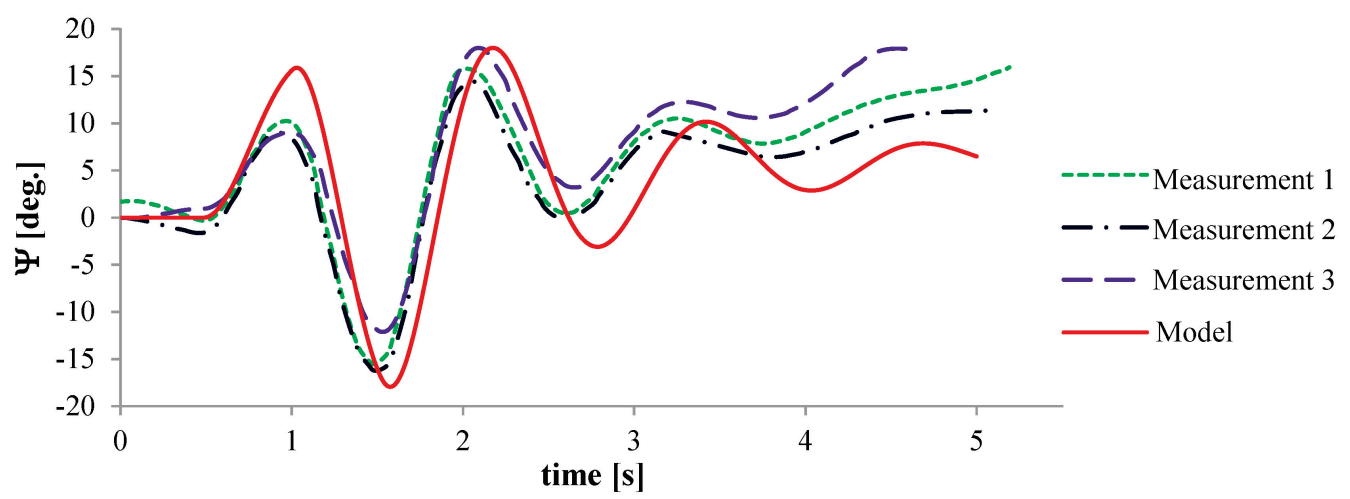

Fig. 10. Change of the yaw angle for the "doublet" signal output to the rudder [own study, 2016]

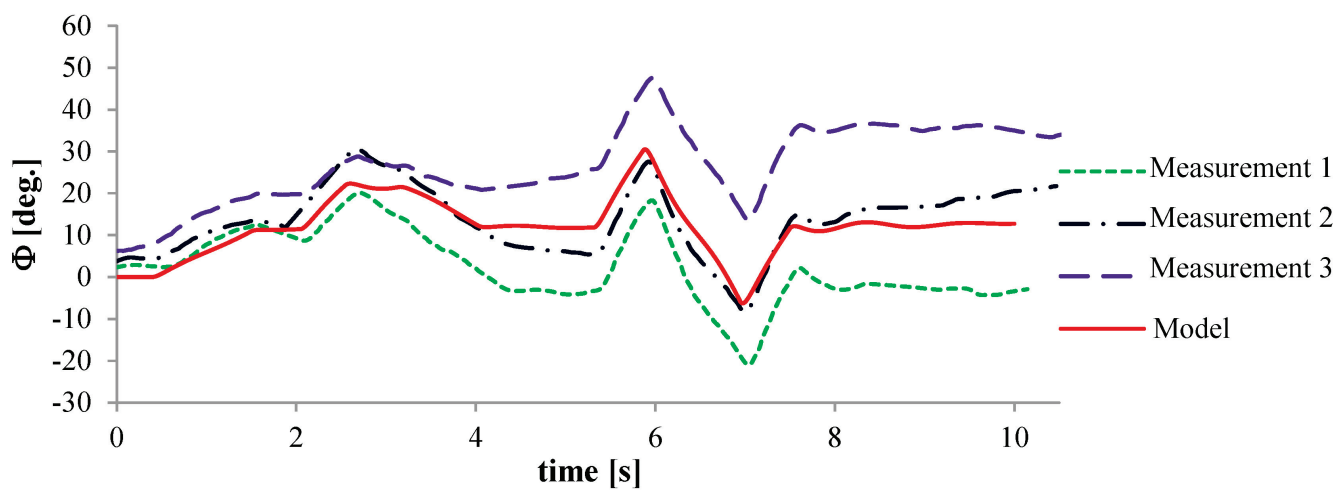

Fig. 11. Change of the roll angle for the "bank-to-bank" signal output to ailerons [own study, 2016] 


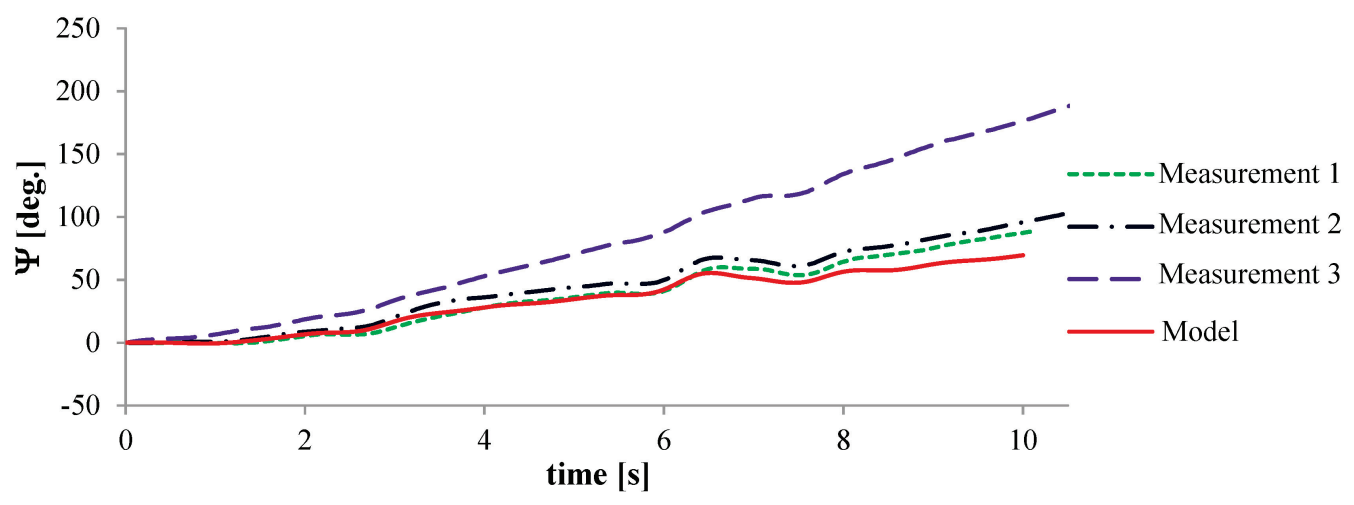

Fig. 12. Change of the yaw angle for the "bank-to-bank" signal output to ailerons [own study, 2016]

Figures 13-16 show sample results of the simulation comparing responses of the aircraft in case of non-uncoupled (classic) and uncoupled control systems. Figures 13 and 14 show changes of spatial orientation angles in response to the forced "3-2-1-1" signal output to both elevators (classic case) and to the right elevator only (uncoupled case). Whereas in the latter case, the left elevator remained in a non-deflected position during the whole time of the simulation. Figures 15 and 16 show simulation results for non-uncoupled (classic system) and uncoupled ailerons. In this case the bank-to-bank signal was output to both ailerons (classic case) and only to the right aileron, for the uncoupled case (left aileron remained in neutral position). As can be seen, utilization of only one control surface reduces the amplitude of the pitch angle change and appearance of cross-couplings in case of roll control. In case of the control in the roll channel, reduction of changes of all spatial orientation angles can be seen.

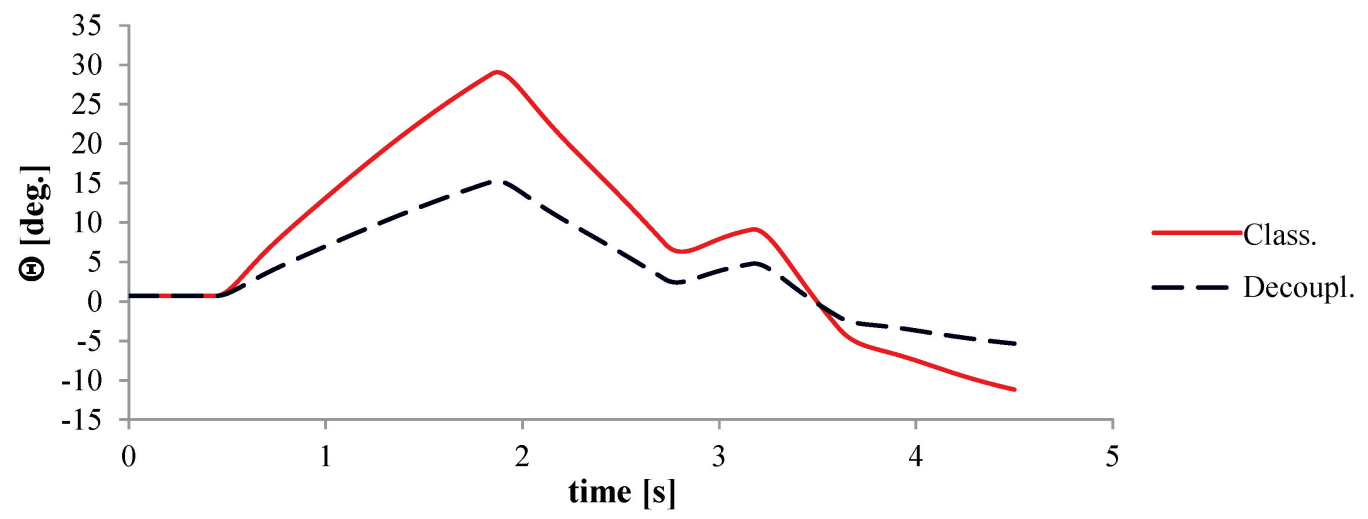

Fig. 13. Change of the pitch angle for the "3-2-1-1" signal output to the elevator [own study, 2016] 


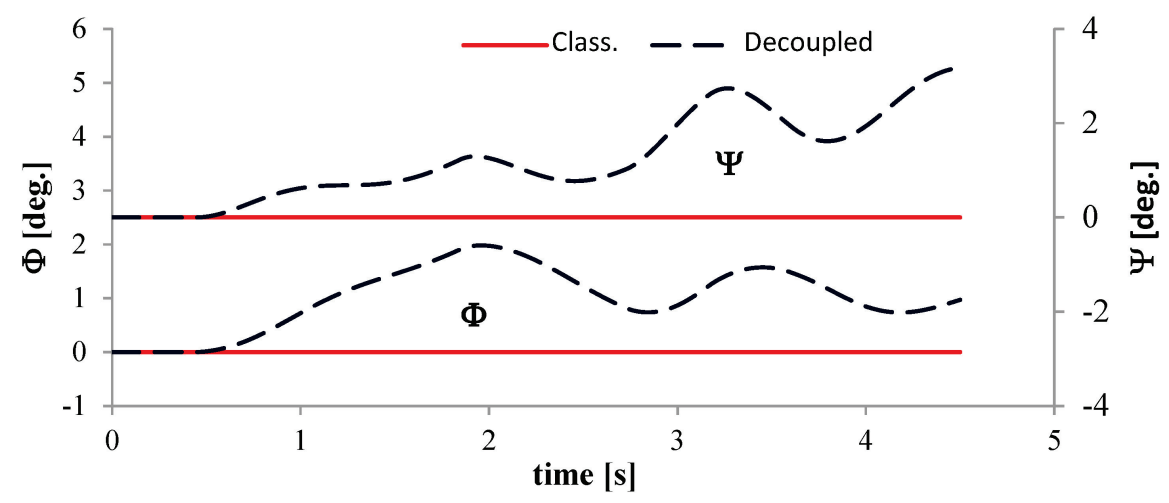

Fig. 14. Change of the roll and yaw angle for the "3-2-1-1" signal output to the elevator [own study, 2016]

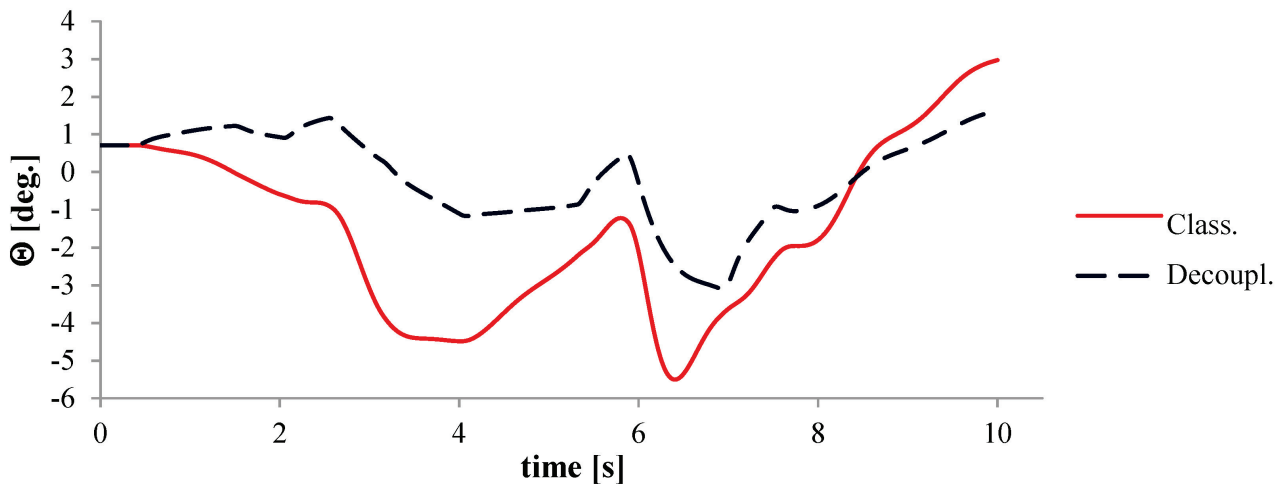

Fig. 15. Change of the pitch angle for the bank-to-bank signal output to ailerons [own study, 2016]

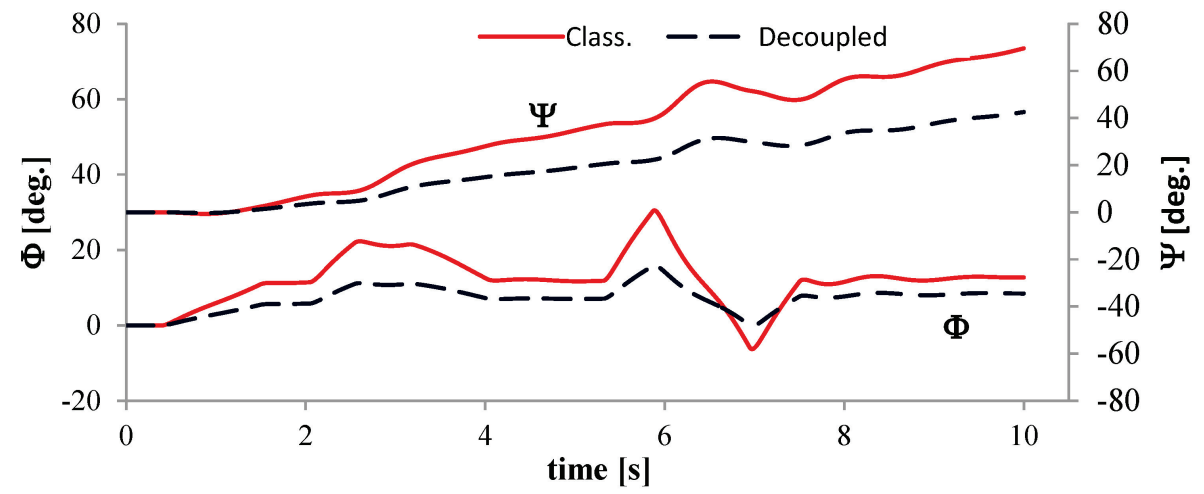

Fig. 16. Change of the roll and yaw angles for the bank-to-bank signal output to ailerons [own study, 2016] 


\section{A SIMULATION MODEL OF AN UNMANNED AIRCRAFT}

A mathematical model of an unmanned aircraft was used to develop a simulation model in the Simulink environment. Apart from the mathematical aircraft model, the simulation model includes a Dryden atmosphere model and the input-output interface module. The input-output interface module is responsible for communication with external hardware such as, flying controls or autopilot and for measuring equipment simulation. Simulation of the measuring equipment is intended to convert ideal variable state signals from the aircraft dynamics model to signals representative for actual measurements. The module performs discretization of signals and generation of noise and measurement errors.

The simulation model has been applied in the test simulator, the design of which permits integration of the software developed in the Simulink environment with the simulator software and enables communication of the integrated model with external hardware over the CANaerospace bus [24] (fig. 17). This allows to perform hardware-in-the-loop studies of the developed control system.

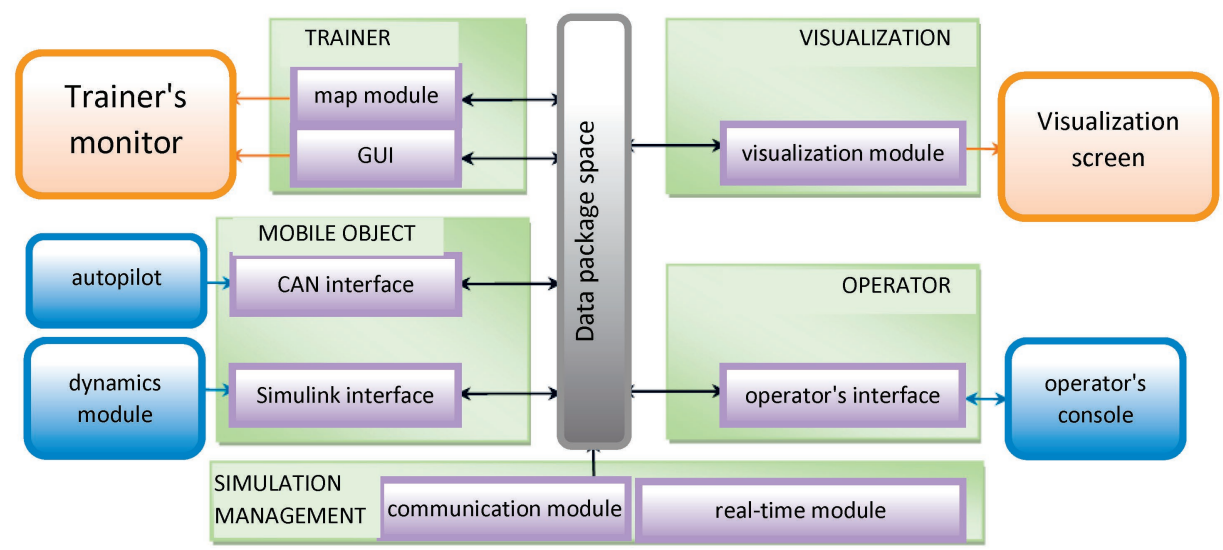

Fig. 17. Modular design of the test simulator software [own study 2016]

A series of test flights were performed in the test simulator in order to test the correct functioning of the whole system. Sample results of one of the tests are shown in figures 18-22. Results illustrate a free flight, during which the operator was tasked with a number of flight course, speed and altitude changes. A flight without malfunctions was simulated, and due to this control surfaces were operating in a non-uncoupled (classic) configuration. Figure 18 shows the flight trajectory in the WGS84 coordinate system. Figures 19 through 22 show recoded waveforms of: IAS, barometric altitude changes, lateral acceleration, yaw angular speed and control variables (deflection of control surfaces and the throttle input) stated as percentage of their respective maximum values. The aileron deflection signal represents the deflection mean value for both ailerons $0.5\left(\delta_{A R}-\delta_{A L}\right)$ [12]. Tests have shown that the model behaves correctly, the simulation runs smoothly and the quality of simulated measurement signals is correct. 


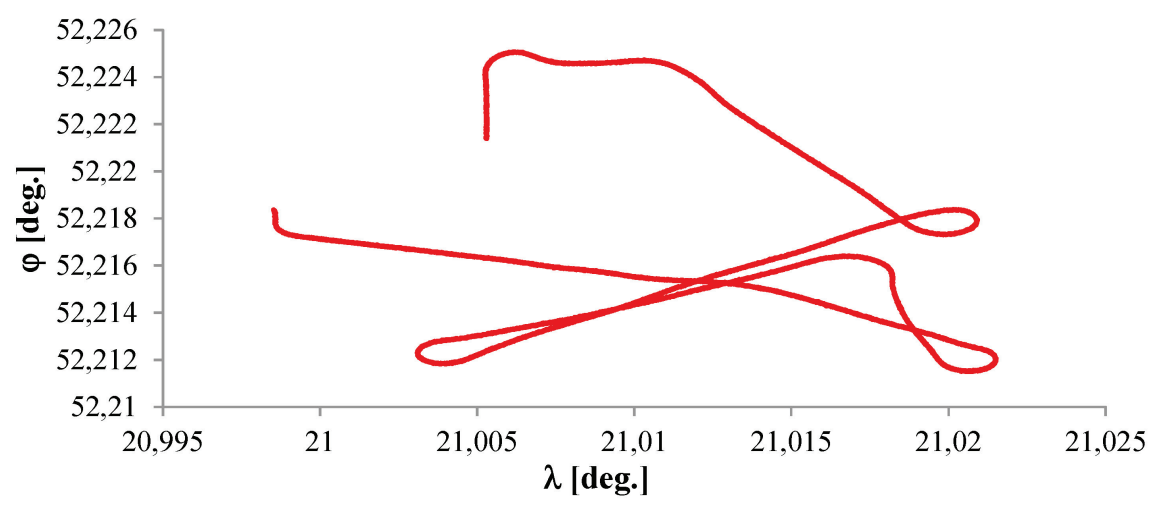

Fig. 18. Trajectory of a test flight in the simulator [own study, 2016]

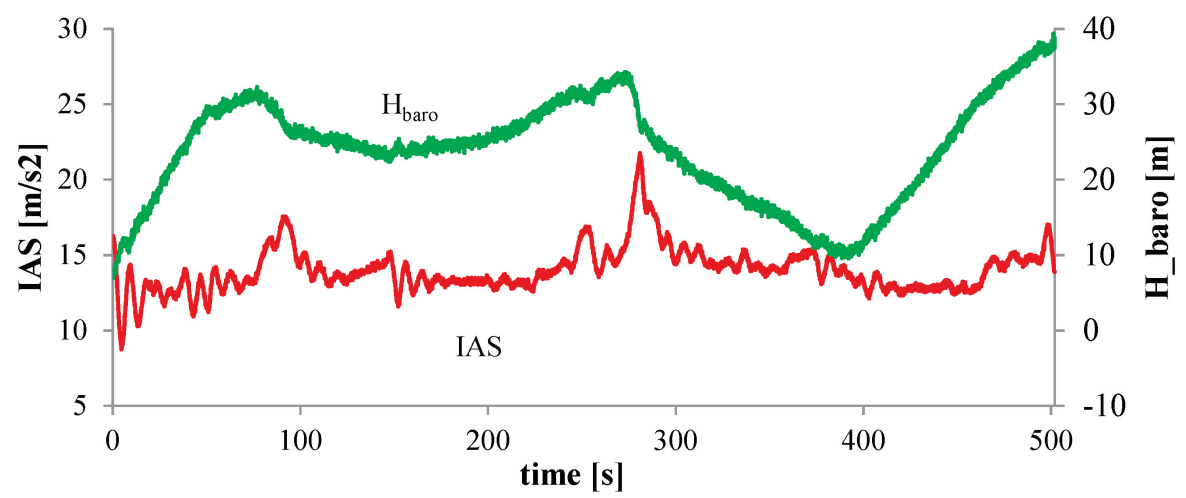

Fig. 19. IAS and barometric altitude waveforms recorded during a test flight on the simulator [own study, 2016]

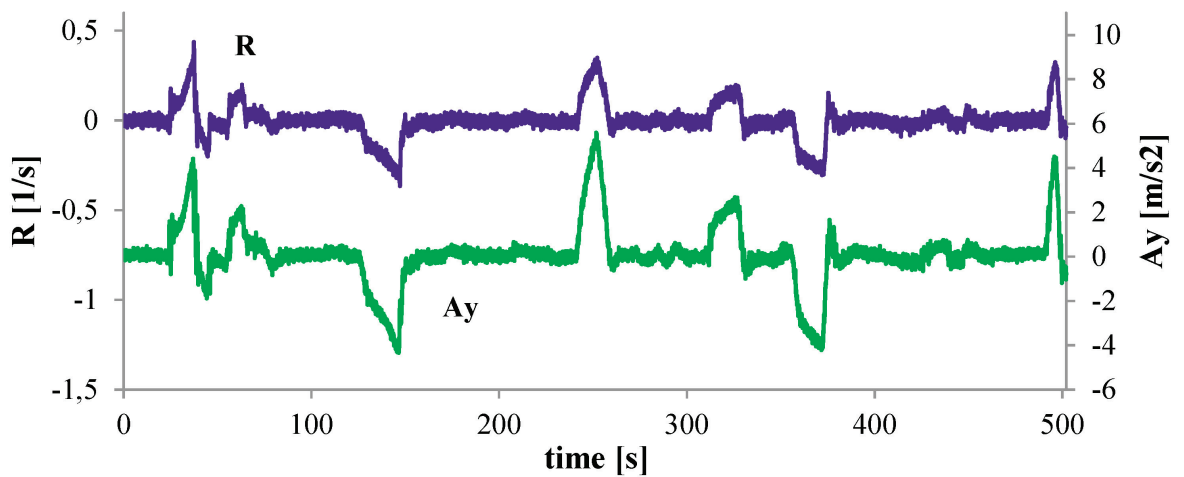

Fig. 20. Yaw speed and lateral acceleration waveforms recorded during a test flight on the simulator [own study, 2016] 


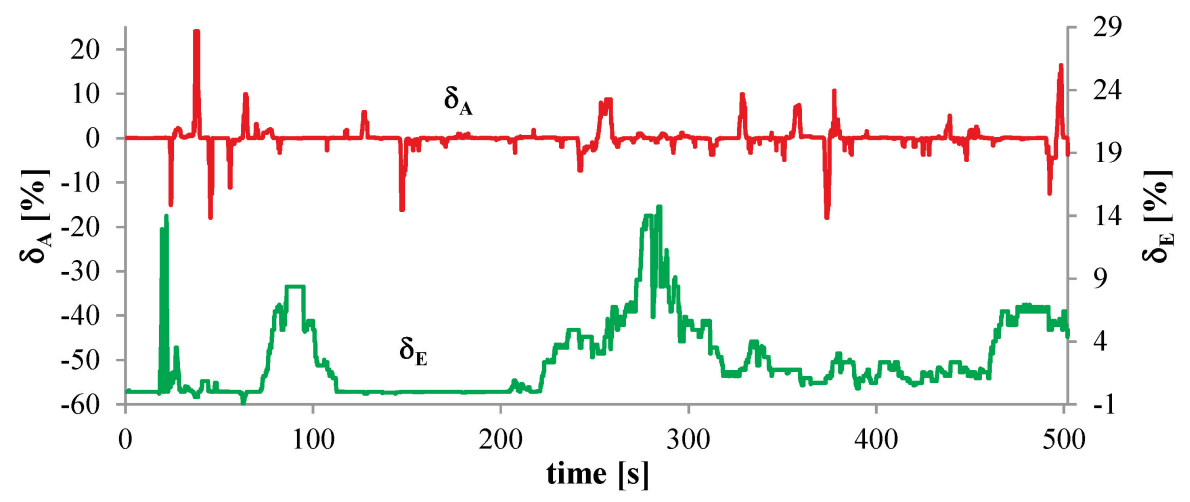

Fig. 21. Aileron and elevator deflection angle waveforms recorded during a test flight on the simulator [own study, 2016]

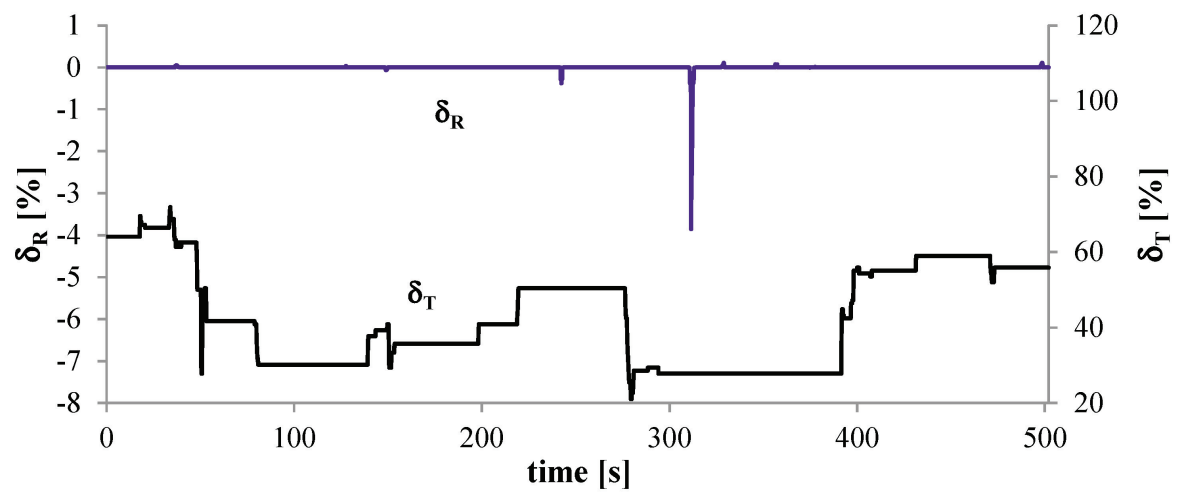

Fig. 22. Rudder deflection angle and throttle input waveforms recorded during a test flight on the simulator [own study, 2016]

\section{CONCLUSIONS}

The paper presented a non-linear model of an unmanned aircraft with decoupled control surfaces. The model utilized an indirect method for controllability derivatives' determination, which facilitates adjustment of derivatives based on in-flight tests and allows for the method to be applied to any aircraft type. Comparison of the results obtained using the model against the results from in-flight tests has shown that the model is correct and that it correctly reflects the behavior of the actual aircraft. The developed model of unmanned aircraft dynamics with decoupled control surfaces can be used for tests of aircraft dynamic properties in control system failure conditions as well as for developing control and reconfiguration algorithms. Tests performed on the test simulator have shown that the model works in real-time and that it may be used for testing of finished control systems using the hardware-in-the-loop method. 


\section{REFERENCES}

[1] Goetzendorf-Grabowski, T., Frydrychewicz, A., Goraj, Z., et al., 2006, "MALE UAV design of an increased reliability level," Aircraft Engineering and Aerospace Technology: An International Journal, vol. 78, No 3, pp. 226-235.

[2] Lin, X., Fulton, N., and Horn, M., 2014, "Quantification of high level safety criteria for civil unmanned aircraft systems," Proceedings of IEEE Aerospace Conference, Big Sky, pp. 1-13.

[3] Loh, R., Bian, Y., and Roe, T., 2009 "UAVs in civil airspace: Safety requirements," IEEE Aerospace and Electronic Systems Magazine, vol. 24, January, pp. 5-17.

[4] Goraj, Z., 2014, "A specialized UAV for surveillance in windy, turbulent environment of the Antarctic coast," Proceedings of the 29th Congress of the International Council of the Aeronautical Sciences Vol I-VI, Curran Associates, Inc, pp. 1-13.

[5] Goraj, Z., Ransom, P., Wagstaff, P., 2002, "From Specification \& Design Layout to Control Law Development for Unmanned Aerial Vehicles - Lessons Learned from Past Experience," Proceedings of European Workshop on Aircraft Design Education, Institute of Technology Linkopings Universitet, pp. 17-21.

[6] Steinberg, M., 2005, "A historical overview of research in reconfigurable flight control," Proceedings of the Institution of Mechanical Engineers, Part G: Journal of Aerospace Engineering, vol. 219, April, pp. 263-275.

[7] Kozak, V., Shevchuk, D., Vovk, V., and Levchenko, M., 2014, “Automation of aircraft control reconfiguration in flight special situations," Proceedings of IEEE 3rd International Conference on Methods and Systems of Navigation and Motion Control, Kiev, pp. 14-17.

[8] Yang, Z., Hua, S., Hongzhuan, Q., and Chengrui, L., 2010, "Control reconfigurability of nonlinear system based on control redundancy," 10th IEEE International Conference on Industrial Informatics (INDIN), Beijing, pp. 815-820.

[9] Burcham, B., 1997, "Landing safely when flight controls fail.” Aerospace America, pp. 20-23.

[10] Zugaj, M., Bibik, P., and Jacewicz, M., 2016, "UAV aircraft model for control system failures analysis," Journal of Theoretical and Applied Mechanics, vol 54, No. 4, pp. 1405-1415.

[11] Cooper, G., and Harper, R., 1969, The Use of Pilot Rating in the Evaluation of Aircraft Handling Qualities," Technical Report TN D-5153, NASA Ames Research Center, Moffet Field, CA,USA.

[12] Nizioł, J., 2005, Dynamika układów mechanicznych (Dynamics of mechanical systems), Komitet Mechaniki PAN (Mechanics Committee of PAN). Instytut Podstawowych Problemów Techniki Polskiej Akademii Nauk (Institute of Fundamental Technological Problems of the Polish Academy of Sciences), Warsaw.

[13] Goraj, Z., 2014, "Flight dynamics models used in different national and internationals projects," Aircraft Engineering and Aerospace Technology, Volume: 86 Issue: 3.

[14] Zugaj, M., and Narkiewicz, J., 2009, "Autopilot for reconfigurable flight control system," ASCE Journal of Aerospace Engineering, vol. 22, January, pp. 78-84.

[15] PN-ISO 1152-1:2014, chapter 1.8.3.2.

[16] Figat, M., Goetzendorf-Grabowski, T., Goraj, Z., 2005, “Aerodynamic calculation of unmanned aircraft," Aircraft Engineering and Aerospace Technology, vol. 77, No 6, pp. 467-474. 
[17] Goetzendorf-Grabowski, T., and Figat, M., “Aerodynamic and stability analysis of personal vehicle in tandem-wing configuration," Proceedings of the Institution of Mechanical Engineers Part G-Journal of Aerospace Engineering, SAGE Publications, vol. on-line, 2016, ss. 1-17.

[18] Analytical Methods a Division of Stark Aerospace, Inc., from http://www.ami.aero/softwarecomputing/amis-computational-fluid-dynamics-tools/mgaero/

[19] XFLR5, from http://www.xflr5.com/xflr5.htm

[20] XFOIL, Subsonic Airfoil Development System, from http://web.mit.edu/drela/Public/web/xfoil/

[21] Goraj, Z., and Cichocka, E., 2016 "Influence of weak and strong gyroscopic effects on light aircraft dynamics," Aircraft Engineering and Aerospace Technology, Vol. 88 Issue: 5, pp. 613-622.

[22] Jategaonkar, R., V., 2006, Flight Vehicle System Identification, A Time Domain Methodology, American Institute of Aeronautics and Astronautics, Reston, Virginia.

[23] Yechout, T., R., 2003, Introduction to Aircraft Flight Mechanics: Performance, Static Stability, Dynamic Stability, and Classical Feedback Control, American Institute of Aeronautics and Astronautics, Reston, Virginia.

[24] Bibik, P., Zasuwa, M., and Żugaj, M., 2013, "Research and training simulator of unmanned quadrotor," 18th IEEE International Conference on Methods and Models in Automation and Robotics, Międzyzdroje, pp. 403-407.

\section{MODEL SAMOLOTU BEZZALOGOWEGO DLA ANALIZY I SYNTEZY REKONFIGURACJI UKLADU STEROWANIA}

\section{Streszczenie}

Niezawodność samolotów bezzałogowych jest czynnikiem decydującym o możliwości wykonywania zadań lotniczych w kontrolowanej przestrzeni powietrznej. Jedną z metod zwiększenia niezawodności samolotów bezzałogowych jest rekonfiguracja układu sterowania, która umożliwia sterowanie samolotem pomimo powstałej awarii. Rekonfiguracja systemu sterowania polega na wykorzystaniu sprawnych powierzchni sterowych do kompensacji skutków awarii oraz sterowania uszkodzonym samolotem. Opracowanie efektywnych algorytmów rekonfiguracji wymaga wykorzystania nieliniowego modelu dynamiki samolotu bezzałogowego, w którym możliwe jest niezależne sterowanie wychyleniem każdej powierzchni sterowej.

W pracy przedstawiono nieliniowy model małego samolotu bezzałogowego o rozprzężonych powierzchniach sterowych. Przestawiono równania dynamiki samolotu oraz oszacowane równania pochodnych sterowności dla każdej z powierzchni sterowych, wyniki testów porównawczych modelu i rzeczywistego samolotu oraz strukturę modelu symulacyjnego. Opracowany model samolotu bezzałogowego może być wykorzystany do opracowania oraz optymalizacji algorytmów sterowania samolotem z uszkodzonym systemem sterowania, oraz badania wpływu awarii na właściwości dynamiczne samolotu.

Słowa kluczowe: dynamika lotu, sterowanie, rekonfiguracja.

"The paper was drafted within the scope of the PBS2/B6/19/2013 project financed by the Narodowe Centrum Badań i Rozwoju (National Center for Research and Development) between 2013 and 2016". 